\title{
INFORMATION TECHNOLOGY SUPPORT FOR SUPPLY CHAINS
}

\author{
KREMLJAK, Z. \& KAFOL, C.
}

Abstract: Supply chain encompasses all activities needed to design, manufacture and deliver a product (or perform a service) using a mechanism or framework for information sharing. In the chapter, we focus on the significance and benefits of operating supply chains as an integral part of the modern manufacturing enterprises and also the importance of information sharing as the major requirement for the effective functioning of supply chains. In order to provide the necessary information technology support for supply chains, the basic concepts and features of agent based technology has been evaluated in order to determine its suitability for the management of supply chains. An overview of multi agent model for the supply chain is presented and the integrated functioning of certain agents resulting in information sharing is demonstrated.

Key words: supply chain, agent technology, information sharing, multi agent system, scheduling functions
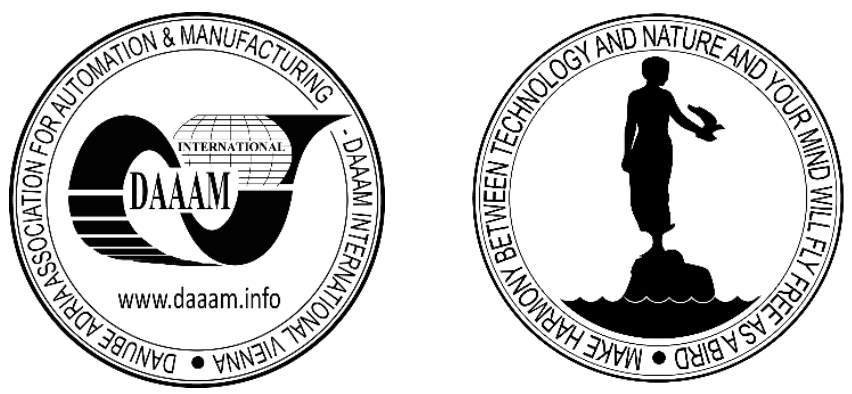

Authors' data: Asst. Prof. Dr. Sc. Kremljak, Z[vonko]; Dr. Sc. Kafol, C[iril], Telekom Slovenije, d. d. (Telekom Slovenia Group, ONE Telecommunications Services - Skopje, MK), Cigaletova 15, SI - 1000 Ljubljana, Slovenia, EU, zvonko.kremljak@s5.net, ciril.kafol@one.mk

This Publication has to be referred as: Kremljak, Z[vonko] \& Kafol, C[iril] (2015). Information Technology Support for Supply Chains, Chapter 02 in DAAAM International Scientific Book 2015, pp.017-030, B. Katalinic (Ed.), Published by DAAAM International, ISBN 978-3-902734-05-1, ISSN 1726-9687, Vienna, Austria DOI: $10.2507 /$ daaam.scibook.2015.02 


\section{Introduction}

In recent decades, globalization, outsourcing, and information technology have enabled many organizations to successfully operate collaborative supply networks in which each specialized business partner focuses on only a few key strategic activities. This inter-organisational supply network can be acknowledged as a new form of organisation (Baumgaertel \& John, 2003).

In order to support its global competitiveness and responsiveness to rapid market changes, every manufacturing enterprise has to be integrated not only with its related management systems such as purchasing, design, production, planning and scheduling, control, transport, resources, personnel, materials, quality etc., but also with its partners, suppliers and customers through heterogeneous software and hardware environments (Nallari \& Griffith, 2013).

A competitive advantage is based on capabilities that provide the necessary grounds of an organization to differentiate itself from its competitors (Marinagi et al., 2014). Manufacturing strategies are therefore shifting to support global competitiveness, new product innovation and rapid market responsiveness. Among the managerial and organizational changes required in the face of global competition, virtual enterprise has emerged to adapt this competitive market environment (Gunasekaran \& Kobu, 2007). Virtual enterprise is an organization created from physically distributed constituents, which are linked electronically to enable interaction and cooperation normally associated with a centralized enterprise (Villa, 2002). The concept of virtual enterprise represents highest-level inter-enterprise integration.

Supply chain encompasses companies and all those activities needed to design, make, deliver and use a product or service (Chopra \& Meindl, 2006). A supply chain typically extends across the multiple enterprises including suppliers, manufacturers, transportation carriers, warehouses, retailers as well as customers and entails sharing forecast, order, inventory, and production information for better coordination of management decisions at multiple points throughout the extended enterprise. The basic characteristics of the supply chain indicate that the efforts associated with the formation of supply chain can be easily extended to the formation of virtual enterprise. Hence, the proposed work intends to focus on the realization of virtual enterprise through the formation of supply chain as the initial step.

The pace of change and the uncertainty about how markets will evolve has made it increasingly important for companies to be aware of the supply chains they participate in and to understand the roles that they play (Buchmeister et al., 2012). Those companies that learn how to build and participate in strong supply chains will have a substantial competitive advantage in their markets. With customers becoming more demanding, the construction of an efficient and integrated supply-chain has assumed paramount importance (Martinez-Olvera \& Shunk, 2006).

Since, the supply chain usually includes more than one company and also various units of an enterprise, communication and information sharing between companies / units at the supplier-customer interface is critically important for overall supply chain performance (Buchmeister \& Palcic, 2013). Collaborating programs, such as vendor managed inventory (VMI), collaborative planning, forecasting, and replenishment 
(CPFR), quick response (QR), and continuous replenishment, increases the level of interaction between companies. All of these programs share a common element, sharing information and decreasing the uncertainty built into information that flows back up the supply chain (Chan \& Chan, 2009).

Information sharing serves as an essential approach for the survival of enterprises and enabler of supply chain integration. With the advancement in information and communication technology, information sharing has become more conceivable. Furthermore, information sharing in supply chains has become more efficient by the global introduction of long-term cooperation and coordination, which leads ultimately to the improvement of companies' competitive advantages. There is a lack of information sharing within companies nowadays, which results in inefficiency of coordinating actions within the units in the company or organization (Lofti et al., 2013).

Agents have revolutionized manufacturing systems. Agent technology provides a natural way to design and implement distributed intelligent manufacturing environments and provides software architecture for managing the supply chain. In distributed intelligent manufacturing systems, the main function of agents is to integrate manufacturing enterprise activities such as design, planning, execution, simulation, distribution, forecasting between suppliers, customers and partners (Shen $\&$ Norrie, 1999). They are also used to represent various manufacturing sources like products, parts and operations to facilitate different manufacturing activities.

With this idea, a research activity has been identified to develop a multi agent system model for designing supply chain, which result in efficient sharing of information and integrated functioning of various units of an organization and also enhancing the communication with other collaborating enterprises. An overview of this work is presented in this paper.

\section{Agents in manufacturing}

Several studies have shown that there is a positive effect of information sharing along the supply chain (Verdicchio \& Colombetti, 2002). Moreover, better integration as well as coordination among the different nodes in the supply chain through use of information technology has also helped to improve performance in these systems. It means information Technology (IT) plays a major role in the formation of the supply chain.

An agent is a software entity that has a set of protocols, which govern the operations of the manufacturing entity, a knowledge base, an inference mechanism and an explicit model of the problem to solve (Shen \& Norrie, 1999). Agents communicate and negotiate with the other agents, perform the operations based on the local available information and may pursue their local goals. This definition has both technical and organizational aspects. Technically, agents possess sufficient knowledge and inferential capability to behave in a manner that would be classified as "intelligent" if performed by a person. Organizationally, agents are entrusted with sufficient authority to make commitments for users. This enables them to represent their principals and adhere to the same corporate rules, policies and procedures required to be followed by people in the organization (Zimmermann et al., 2006). 
The common characteristics possessed by an agent are:

Autonomy: The agent is able to do at least part of its functionality independently and follow goals autonomously.

Intelligence: The agent has some specialized knowledge in one or more application fields.

Interaction: The agent is able to collect information or to react on conditions of its environment.

Reactivity: An agent must be capable of reacting appropriately to inputs from its environment.

Pro-activity / goal-orientation: An agent does not just react to changes to its environment but it takes the initiative.

Learning: An agent has to change its behaviour based on its previous experience.

Mobility: Mobility enables an agent to transport itself from one node of a network to another.

Communication / cooperation: An agent can use the communication capability to make contact with its environment.

A multi agent system views the supply chain as composed of a set of intelligent (software) agents, each responsible for one or more activities in the supply chain and each interacting with other agents in planning and executing their responsibilities. An agent is an autonomous, goal-oriented software process that operates asynchronously, communicating and coordinating with other agents as needed (Fox et al., 2000).

\section{Literature survey}

A literature survey has been carried out on reported works related to the application of agent technology for supply chain management. Though a considerable number of works have been reported, we have included only those papers, which are related to our proposed work, which still are not exhaustive.

Coordination plays a pivotal role in successful design and implementation of supply chains, especially for those that are formed by independent and autonomous companies. Chan and Chan (2009) analysed the effects of negotiation-based information sharing in a distributed make-to-order manufacturing supply chain in a multi-period, multi-product types environment, which is modelled as a multi-agent system. Information can only be exchanged through negotiation in the agent-based framework with delivery quantity and due date flexibility. Four schemes, namely, stochastic model (STO), flexibility in delivery quantity and due date without information sharing (FLEX_NI), flexibility in delivery quantity and due date with partial information sharing (FLEX_PI), and flexibility in delivery quantity and due date with full information sharing (FLEX_FI), are considered. Simulation results indicate that FLEX_PI in the system has comparable performance in terms of total cost and fill rate against FLEX_FI. Verdicchio and Colombetti (2002) also stress that information sharing as a critical factor for successful business process management. They argue that one of the most effective ways to achieve the information sharing is to build an agent-based framework, which models the dynamic structure of today's supply chain networks. 
Supply chain decisions are improved with access to global information. However, supply chain partners are frequently hesitant to provide full access to all the information within an enterprise (Gupta et al., 2001). A mechanism to make decisions based on global information without complete access to that information is required for improved supply chain decision making. Mobile agents can support this requirement and these are the programs that can be initiated on a single host and then migrate from host to host over a network. At each host, a process can be spawned which will provide a "black-box" view into that host's information. This provides access to necessary information, while maintaining privacy for company sensitive information. Gupta et al. have discussed about mobile agents and how they are useful in designing and managing the supply chain. The Supply Chain Agent Decision Aid System (SCADAS) is presented as a tool to provide the flexibility of mobile agents while protecting company sensitive information.

Savarimuthu et al. (2006) have described the architecture of agent-based workflow system that can be used for web service composition. In the context of an example from the apparel manufacturing industry, they have demonstrated how web services can be composed and used. They suggest that with the advent of web services, more and more business organizations make their services available on the internet through web services and also use other services that are available on the corporate intranet.

Allwood and Lee (2005) have proposed a new agent for the study of competitive supply chain network dynamics. The novel features of the agent include the ability to select between competing vendors, distribute orders preferentially among many customers, manage production and inventory, and determine price, based on competitive behaviour. The structure of the agent is related to existing business models and sufficient details are provided to allow implementation.

Caridi et al. (2005) carried out a study of the Collaborative Planning Forecasting and Replenishment (CPFR) process for trading partners (belonging to the same supply chain) who are willing to collaborate in exchanging sales and order forecasts. The hurdles that arose in implementing CPFR in field applications indicate the need for providing collaboration process with an intelligent tool to optimize negotiation. To fulfil the need, two multi-agent models are proposed, according to different degrees of agents' capabilities. Through simulation studies it is indicated that the agents-driven negotiation process (by comparison with CPFR without intelligent agents) benefits in terms of costs, inventory level, stock-out level and sales.

Swaminathan et al. (1998) have described a simulation-based framework for developing customized supply chain models from a library of software components. These components capture generic supply chain processes and concepts, thereby promoting modular construction and reuse of models for wide range of applications. Using these components it is possible to incorporate supply, process and demand uncertainty as well as integrate analytic and heuristic decision procedures. The multiagent approach proposed in the work enables performance to be analysed from a variety of organizational perspectives.

Ronald et al. (2006) have shown that an agent-based concept is suited to reduce negative effects of disruptive events in supply chains. While agent technology supports 
the autonomy of supply chain partners it also offers mechanisms to both pull and push event-related information. Two different prototype implementations of the agent-based concept are used to assess the benefits of an agent-based approach to supply chain event management.

Baumgaertel and John (2003) have introduced an approach for highly efficient simulation of supply networks in which several nodes use advanced planning and scheduling (APS) systems. APS systems communicate only with the ERP system they sit on top of it. If APS systems would be able to communicate with each other, qualitatively new processes for planning collaboration in supply nets could emerge. Further, simulation is accepted to be a useful approach for support of business process design. With this background, they have augmented an existing, agent-based simulation system by an APS component.

Belecheanu et al. (2005) presented a case study on application of agent-based modelling to the management and optimization of a corrugated-box manufacturing plant. An agent-based tool was developed by Eurobios to model and simulate plant operations at packaging plant. As a result, the plant management was able to take decisions that led to a reduction in warehouse levels by over $35 \%$ without compromising on-time-in full delivery.

Saturated markets, the difficulty to make sales figures predictable, as well as highest adherence to delivery times and production quality are only a few of the features of the competition, companies are being exposed to. For this a multi-agentbased manufacturing management system, the models of the single agents, and algorithms for the agent-based, decentralized dispatching of orders, strategies and data management concepts as well as their integration into the supply chain management, are expected to provide the solutions (Heinrich et al., 2005). The authors have given functionality and data management of the job order agent and optimization strategies.

Santa-Eulalia et al. (2007) have discussed the potential of agent-based simulation in the domain of supply chain planning and proposed some conceptual modelling constructs aiming to explore the possibility of agent-based simulation for employing in the context of distributed supply chain planning. The proposed conceptual modelling constructs defines some high level building blocks for understanding, designing and implementing practical simulations in supply chain planning systems. Potok et al. (2001) presented agent architecture in support of lean operations across manufacturing supply chains. The architecture addresses the issue of heterogeneous information management, the need for analysing mixed manufacturing approaches, and efficiency and accuracy trade-offs of analysis methods. The work proposes five distinct layers to address these requirements: an XML/RDF/DAML Information Access Layer, a Resource Vector Representation Layer, an Analysis Layer, a Coordination Layer, and a Visualization Layer. The proposed work is based on rich representation of manufacturing resources and advanced analysis techniques.

Zhang et al. (2006) have presented an approach that would enable manufacturing organizations to dynamically and cost-effectively integrate, optimize, configure, simulate, restructure and control not only their own manufacturing systems but also their supply networks, in a coordinated manner to cope with the dynamic changes occurring in a global market. This is realized by a synergy of two emerging 
manufacturing concepts: agent-based agile manufacturing systems and emanufacturing. The concept is to represent a complex manufacturing system and its supply network with an agent-based modelling and simulation architecture and to dynamically generate alternative scenarios with respect to planning, scheduling, configuration and restructure of both the manufacturing system and its supply network based on the coordinated interactions amongst agents.

Macal and North (2006) described agent-based modelling and simulation as a new approach to modelling systems comprised of autonomous, interacting agents. They also presented a tutorial describing the theoretical and practical foundations of ABMS, identify toolkits and methods for developing ABMS models, and provide some thoughts on the relationship between ABMS and traditional modelling techniques. Multi-agent systems (MAS) perfectly suit the demands for global flexibility, cooperation and, at the same time, local autonomy and hence, offer new perspectives compared to conventional, centrally organized architectures in the scope of supply chain management (Ta et al., 2005). Besides the functional requirements like an integrated supply chain scheduling, non-functional requirements like the reliability and the flexibility of the system are also met.

The two major outcome of the literature survey is that information sharing is most important requirement of efficient supply chain and multi agent modelling is most suitable for designing of supply chains. Further it is found that majority of the reported works deals with activities related to inventories and it is necessary to concentrate on those units of organization where manufacturing activities, in particular shop floor activities are involved which are in need of agent technology. The approach should be from the point of view of production engineers. It is also felt that the advanced aspects of agent technology are used only for information sharing and needs to be used for intelligence in manufacturing.

\section{Agents proposed for the current work}

As there are several analogies between units of a company in a business network and an agent, the Multi-Agent System paradigm can be a valid approach for modelling supply chain networks (Verdicchio \& Colombetti, 2002). It views the supply chain as composed of a set of intelligent agents, each responsible for one or more activities in the supply chain and each interacting with other agents in planning and executing their responsibilities. For the proposed work a set of agents have been identified each performing specific function with a set of inputs and out puts. The overall frame wok of operations and integration of the agents has been presented in Fig. 1.

The explanations for the components shown in Fig. 1 are:

SFA - Sales Forecasting Agent, COA - Customer Order Agent, MPSA - Master Production Scheduling Agent, RCPA - Rough Cut Planning Agent, STA - Stocks Agent, PDA - Product Data Agent, BOM - Bills Of Materials Agent, TPA - Time Phasing Agent, LIST-O - List of items to be ordered period wise, VNDR - Vendor Rating Agent, VNDA - Vendor Data Agent, LIST-OV - List of Ordering items with selected Vendors, PRCA - Purchase Agent, LIST-M - List of Manufactured items period wise, PDDA - Product Design and development Agent, CPA - Capacity 
Planning Agent, PPA - Process Planning Agent, SCHA - Scheduling Agent, IES Industrial Engineering Support, MFGKB - Manufacturing Knowledge Base.

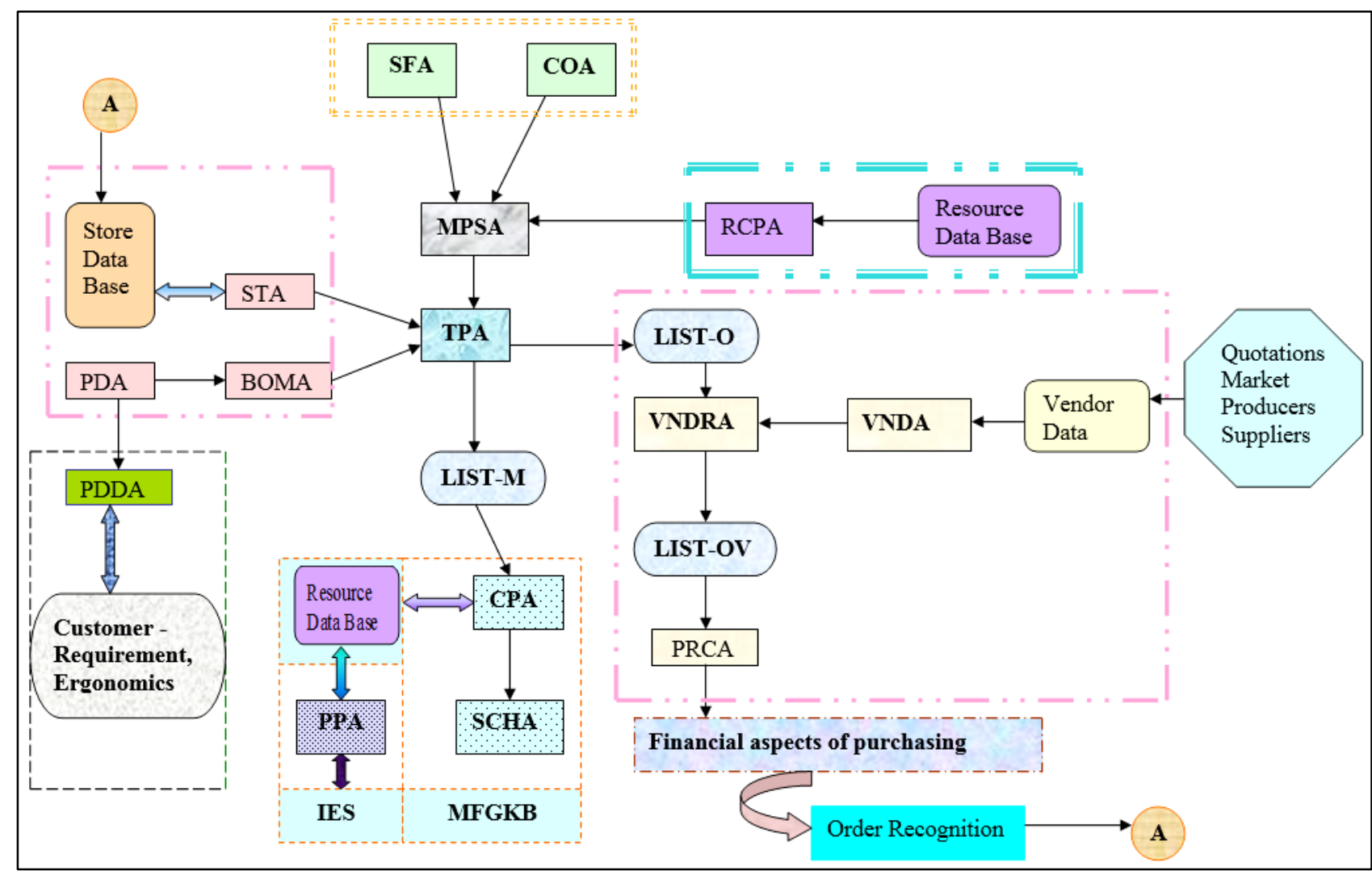

Fig. 1. Schematic view of network of agents for the supply chain in the proposed work

In the current work only those agents which are responsible for storage and purchasing activities are highlighted with the help of concepts of MRP (Material Requirements Planning). The following are the details of agents developed for the work reported in this paper.

\subsection{Stock agent (STA)}

This agent is responsible for storing the information regarding the available stock (components / material) and for giving access to the data to other agents through negotiation or by sending standard massages. This agent is also responsible for updating the data before and after each purchasing activity. The updated information is available as output and accessed by agents for time phasing, and Master Production Scheduling.

\subsection{Agent for the generation of master production schedule (MPSA)}

Agent for Manufacturing Production Scheduling play an important role for the manufacturing activity and the whole process of agent based approach initiates from this stage for atomization. The agent basically starts receiving the data and information about customer orders, forecast, available capacity from the concerned agents (COA, SFA, and RCPA), see Fig. 2. Thus received information is used for the generation of Master production Schedule for given part. This agent transfer its output to TPA agent. 


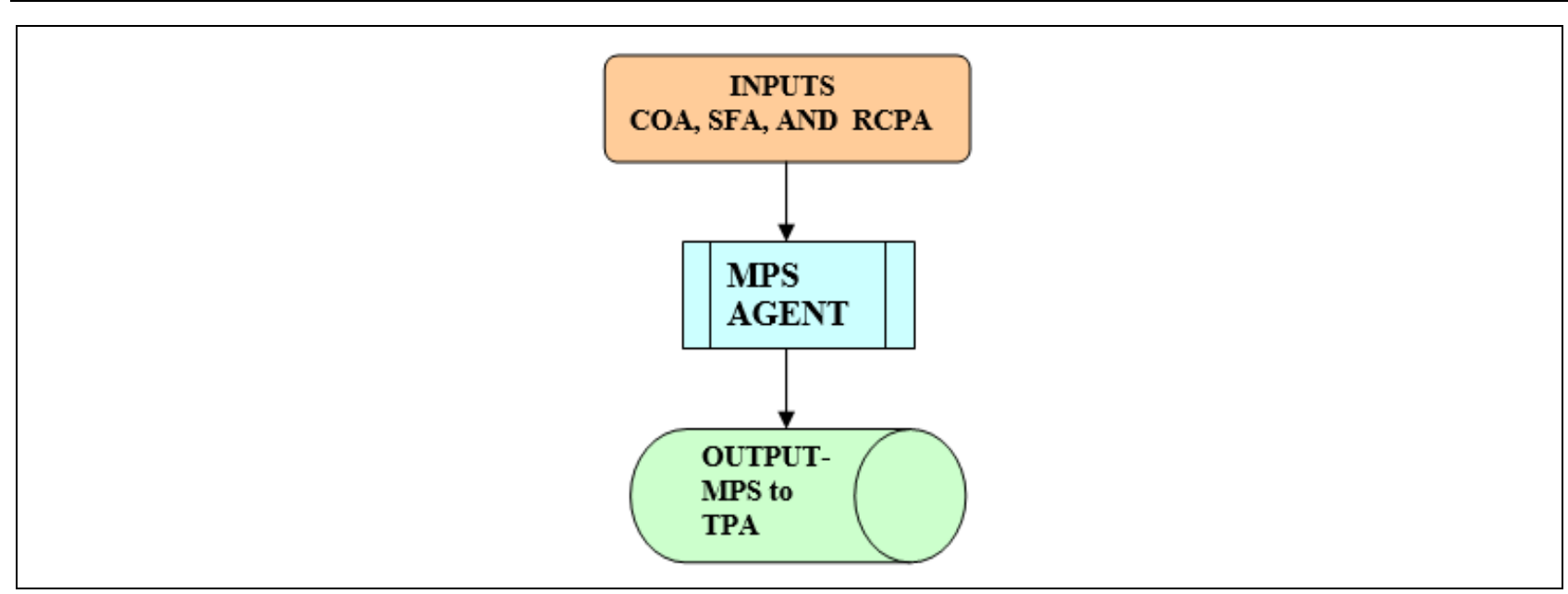

Fig. 2. Input and output of MPSA

\subsection{Agent for rough cut capacity planning (RCPA)}

This agent provides a Rough Cut Capacity Plan, which will be developed after collecting the relevant data about the recourses from the related agents. This agent also prepares the capacity planning information required for agents of production planning activities in particular, scheduling.

\subsection{Product data agent (PDA)}

This agent is responsible for product data acquisition from PDDA regarding product structure, dimensions, tolerances and other specifications. This agent is the basic agent meant for collecting and storing almost all the required information about the product for any reference before, during, and after manufacturing activities. The agent updates the information continuously so that the other agents which need the product data can access by sending predefined messages.

\subsection{Agent for bill of material (BOMA)}

This agent gets the required information about a given part from PDA for processing and computing the bill of material of the part. The agent also does listing of assemblies and subassemblies parts and raw materials needed for a given end product.

\subsection{Agent for time phasing (TPA)}

The functions of this agent includes collection of information for its tasks from other agents related to bills of material, product data, stores, manufacturing production scheduling etc. (Fig. 3). This agent processes the information and through time phasing of planned orders determines two lists; period wise list of items to be purchased and period wise list of items to be manufactures.

\subsection{Agent for vendors data (VNDA)}

Vendor data agent is an independent agent interacting with the different suppliers available through network and acquires information about the suppliers for future reference and usage. Specific data includes Cost, Delivery, Quality and Purchase terms. It presents the data as item wise list of potential vendors. 


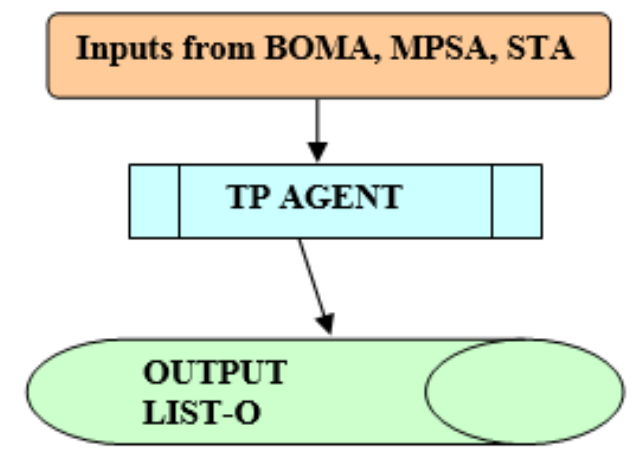

Fig. 3. Input and output of TPA

\subsection{Agent for vendor rating (VNDR)}

This agent performs the process of vendor rating for a given item. It collects data about different vendors through negotiation or by sending standard message to VNDA (see Fig. 4) in a specific format. It uses a well-defined procedure based on the recommended values of weightings specified for the following parameters: Cost, Quality, and Lead Time.

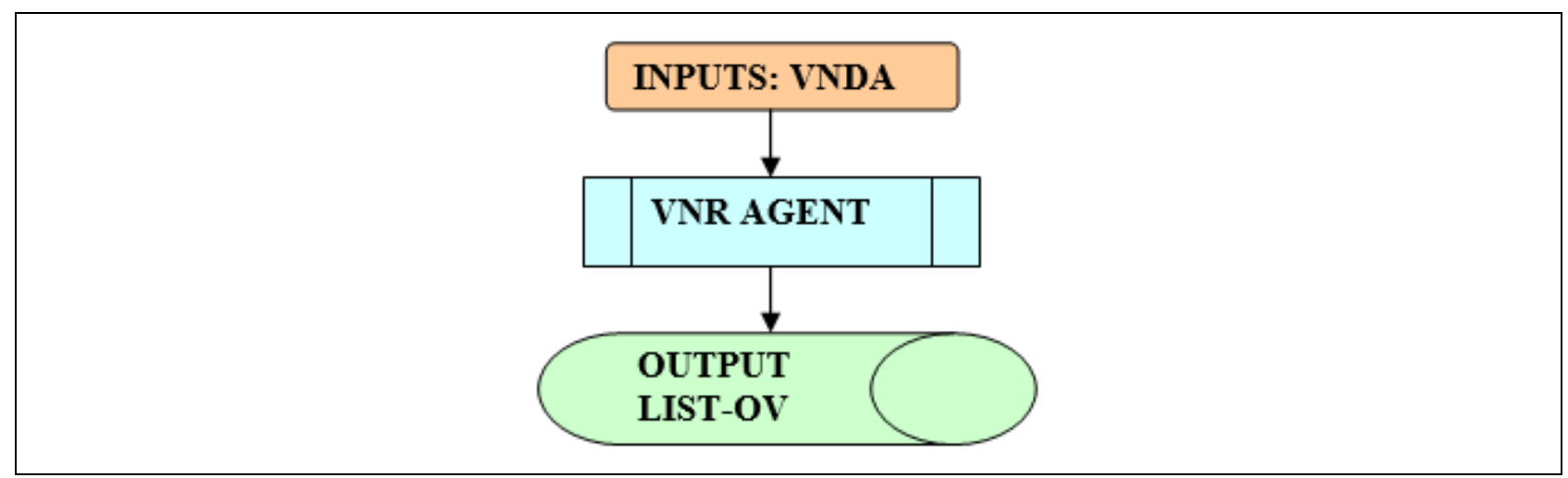

Fig. 4. Input and output of VNDR

\section{MRP functions through agents}

As mentioned above, agents communicate and negotiate with the other agents, perform the operations based on the local available information and may pursue their local goals. For manufacturing activity in an enterprise, the agent technology can help improving the responsiveness, economy of speed and quality of work provided the software agent be suitably modelled.

The agents described in the previous section are expected to perform activities related to purchasing activities based on MRP concepts. The activities performed are development of rough cut capacity planning, master production schedule, time phasing of orders for the preparation of period wise list of items to be purchased, identification of vendors, vendor rating and selection of vendor for each item and preparation of purchase orders.

The MPSA draws the information from SFA and COA and also from RCPA. The TPA agent then obtain all required data and information from STA and MSPA using 
standard messages. Apart from these, the TPA also has to link with BOMA for product data files.

The TPA generates a list of period wise items form purchased and manufactured items. The list of items to be purchased will be sent to the VDRA for the selection of vendors, which in turn will communicate VNDA. The VNDA will independently interact with potential vendors on the network along with data query files. This process continues until satisfactory level of data acquisition occurs to a significant level. The data of potential vendors will be transferred to VDRA for performing vendor rating based on the parameters such as unit cost, lead time, transportation cost and quality in terms of defective percentage. The required weightings for these parameters are obtained though interactive mode. The results of each vendor are grouped for vendor performance rating (VPR).

The TPA, which has collection of logical procedures, generates the required output leading to purchasing and scheduling activities. This output has been made possible through effective sharing of information between all the agents. For this, the required information has been represented as objects using the concepts of objectoriented programming. As a typical example, the structure used for representing the item and vendor are given below.

Structure for the item
itemname: character type //string variable
Item code: integer type // unique code to distinguish item
Vendors: character arrays // list of vendors for the items
Measuredunits: floating type variable // specification used for ordering.
Parentitem: character type //string variable
Childitems: character arrays // list of vendors for the items
Endproduct(s): character arrays // list of vendors for the items
Structure for the vendors
itemname: character type //string variable
Item code: integer type // unique code to distinguish item
Vendorname: character type // string variable
cost: float type // cost specification
leadtime: integer type // information of vendor lead time in days
quality: integer type // number of defective probable
Rating for an Item // a value for decision making

\section{Results and discussion}

The high level of complexity of supply chains and the inherent risks that exist in both the demand and supply of resources are recognized as major limiting factors in achieving high levels of supply chain performance. The use of modern information technology decision support systems is fast becoming an indispensable tool for designing and managing complex supply chain systems.

The collective functioning of all the proposed agents is simulated for the product $\mathrm{P}$ that has four components as shown in Fig. 5. The programs composed for the various agents are executed for the Master Production Schedule shown in Table 1. A list of vendors was used for these components. The outputs as a list of purchased items and a 
Kremljak, Z. \& Kafol, C.: Information Technology Support for Supply Chains

list of manufactured items are shown in Table 2 and Table 3 respectively. The results are verified with the calculation, carried out from a reliable source.

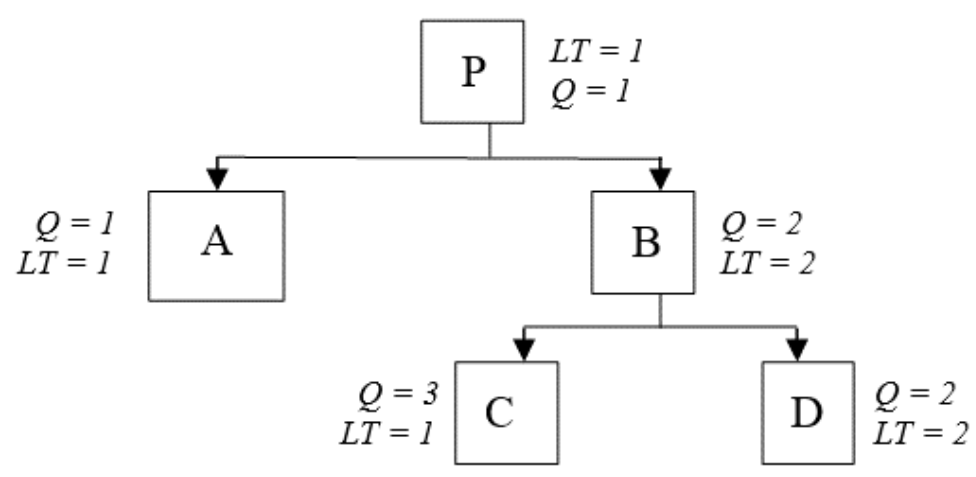

Fig. 5. Bill of materials for product $\mathrm{P}$

\begin{tabular}{|l|c|c|c|}
\hline Time [week] & 10 & 11 & 12 \\
\hline Quantity & 30 & 50 & 50 \\
\hline
\end{tabular}

Tab. 1. Master Production Schedule for product $\mathrm{P}$

Assumptions made are: on hand inventory for $\mathrm{P}=0, \mathrm{~A}=10, \mathrm{~B}=20, \mathrm{C}=0, \mathrm{D}=0$.

\begin{tabular}{|c|c|c|c|}
\hline Time $[$ week $]$ & Item & Quantity & Vendor \\
\hline 5 & D & 120 & V1 \\
\hline 6 & D & 200 & V1 \\
\hline 6 & C & 180 & V2 \\
\hline 7 & D & 200 & V1 \\
\hline 7 & C & 300 & V2 \\
\hline 8 & C & 300 & V2 \\
\hline 8 & A & 40 & V3 \\
\hline 9 & A & 50 & V3 \\
\hline 10 & A & 50 & V3 \\
\hline
\end{tabular}

Tab. 2. List of items to be purchased

\begin{tabular}{|c|c|}
\hline Time [week] & Quantity \\
\hline 7 & 100 \\
\hline 8 & 100 \\
\hline 9 & 100 \\
\hline
\end{tabular}

Tab. 3. List of items to be manufactured

\section{Conclusion}

Business value of information technology continues to stimulate interest and debate among both academics and practitioners. Supply chains encompass all those activities needed to design, manufacture and deliver a product or service and need a mechanism or framework for information sharing. Agent-based manufacturing is a new 
way of thinking about and applying information. With this idea, an attempt is made to provide a multi agent system model for the supply chain management.

In the proposed model, each agent performs a specific function of the organization and share the information with other agents. There by the most important requirement of effective supply chain, i.e. information sharing is achieved in the proposed model. At the same time, this agent-based approach provides reliable and agile systems, which will enable manufacturing organizations of the future to accommodate ever-changing needs of their customers.

In the current work, a part of the model related to purchasing activity is highlighted with suitable results. The other parts of the model such as functions related to process planning and scheduling activities for the list of items to be manufactured will be presented in our future publications.

\section{References}

Allwood, J. M. \& Lee, J. H. (2005). The design of an agent for modelling supply chain network dynamics. International Journal of Production Research, Vol. 43, No. 22, 4875-4898

Baumgaertel, H. \& John, U. (2003). Combining agent-based supply net simulation and constraint technology for highly efficient simulation of supply networks using APS systems, Proceedings of the 2003 Winter Simulation Conference, Vol. 2, 1765-1773, New Orleans

Belecheanu, R.; Luck, M. \& Darley, V. (2005). Agent-based factory modelling: Eurobios and SCA Packaging - A Case study, AgentLink III, 1-11, www.agentlink.org, accessed on: 2014-09-23

Buchmeister, B.; Friscic, D.; Lalic, B.; Palcic, I. (2012). Analysis of a three-stage supply chain with level constraints. International Journal of Simulation Modelling, Vol. 11, No. 4, 196-210

Buchmeister, B.; Palcic, I. (2013). Bullwhip effect simulation of a supply chain with level constraints, In: DAAAM International Scientific Book 2013, Katalinic, B.; Tekic, Z. (Eds.), 133-148, DAAAM International Publishing, Vienna

Caridi, M.; Cigoloni, R. \& De Marco, D. (2005). Improving supply-chain collaboration by linking intelligent agents to CPFR. International Journal of Production Research, Vol. 43, No. 20, 4191-4218

Chan, H. K. \& Chan, F. T. S. (2009). Effect of information sharing in supply chains with flexibility. International Journal of Production Research, Vol. 47, No. 1, 213-232 Chopra, S. \& Meindl, P. (2006). Supply Chain Management, $3^{\text {rd }}$ edition, Prentice-Hall, Upper Saddle River

Fox, M. S.; Barbuceanu, M. \& Teigen, R. (2000). Agent-oriented supply chain management. The International Journal of Flexible Manufacturing Systems, Vol. 12, No. 2-3, 165-188

Gunasekaran, A. \& Kobu, B. (2007). Performance measures and metrics in logistics and supply chain management: a review of recent literature (1995-2004) for research and applications. International Journal of Production Research, Vol. 45, No. 12, 28192840

Gupta, A.; Whitman, L. \& Agarwal, R. K. (2001). Supply chain agent decision aid system, Proceedings of the 2001 Winter Simulation Conference, 553-559, Arlington 
Heinrich, S.; Durr, H.; Hanel, T. \& Lassig, J (2005). An agent-based manufacturing management system for production and logistics within cross-company regional and national production networks. International Journal of Advanced Robotic Systems, Vol. 2, No. 1, 7-14

Lofti, Z.; Mukhtar, M.; Sahran, S. \& Zadeh, A. T. (2013). Information sharing in supply chain management, Procedia Technology, Vol. 11, 298-304

Macal, C. M. \& North, M. J. (2006). Tutorial on agent based modeling and simulation part 2: How to model with agents, Proceedings of the 2006 Winter Simulation Conference, 73-83, Monterey

Marinagi, C.; Trivellas, P. \& Sakas, D. P. (2014). The Impact of Information Technology on the Development of Supply Chain Competitive Advantage. Procedia Social and Behavioral Sciences, Vol. 147, 586-591

Martinez-Olvera, C. \& Shunk, D. (2006). Comprehensive framework for the development of a supply chain strategy. International Journal of Production Research, Vol. 44, No. 21, 4511-4528

Nallari, R. \& Griffith, B. (2013). Clusters of Competitiveness, The World Bank, ISBN 978-1-4648-0049-8, Washington

Potok, T. E.; Ivezic, N. D. \& Samatova, N. F. (2001). Agent-based architecture for flexible lean cell design, analysis and evaluation, In: Global Engineering, Manufacturing and Enterprise Networks, Mo, J. P. T.; Nemes, L. (Eds.), 181-188, Springer Science+Business Media, New York

Santa-Eulalia, L.-A.; Frayret, J.-M. \& D'Amours, S. (2007). Agent-based simulation for distributed supply chain planning: conceptual modeling, analysis and illustration, CIRRELT (Interuniversity Research Centre), Quebec

Savarimuthu, B. T. R.; Purvis, M. \& Purvis, M. (2006). Agent based web service composition in the context of a supply-chain based workflow. Information Science Discussion Paper Series, No. 4, 9 pages, University of Otago

Shen, W. \& Norrie, D. H. (1999). Agent-based systems for intelligent manufacturing: A state-of-the-art survey. Knowledge and Information Systems, Vol. 1, No. 2, 129-156 Swaminathan, J. M.; Smith, S. F. \& Sadeh, N. M. (1998). Modeling supply chain dynamics: a multiagent approach. Decision Sciences, Vol. 29, No. 3, 607-632

Ta, L.; Chai, Y. \& Liu, Y. (2005). Multi-agent-based architecture and mechanism for coordination and execution in agile supply chain operational management, Proceedings of the 2005 International Conference on e-technology, e-commerce and e-service (EEE '05), 400-403, Hong Kong

Verdicchio, M. \& Colombetti, M. (2002). Commitments for agent-based supply chain management, ACM SIGecom Exchanges, Vol. 3, No. 1, 13-23

Villa, A. (2002). Emerging trends in large-scale supply chain management. International Journal of Production Research, Vol. 40, No. 15, 3487-3498

Zhang, D. Z.; Anosike, A. I.; Lim, M. K. \& Akanle, O. M. (2006), An agent-based approach for e-manufacturing and supply chain integration. Computers \& Industrial Engineering, Vol. 51, No. 2, 343-360

Zimmermann, R.; Winkler, S. \& Bodendorf, F. (2006). Agent-based supply chain event management - concept and assessment, Proceedings of the $39^{\text {th }}$ Annual Hawaii International Conference on System Sciences, Vol. 2, 10 pages, Kauia 